metabolism and schizophrenia. In their effort to summarise a complicated field some detail was lost, which leads to the false impression that the original cytosolic phospholipase $A_{2}$ gene study (Hudson et al, 1996) was not replicated. A brief review of the literature supports cytosolic phospholipase $\mathbf{A}_{2}$ as a candidate gene for schizophrenia.

Cytosolic phospholipase $A_{2}$, unlike many other phospholipase $A_{2}$ enzymes, possesses a number of properties which suggest an important role in cellular signal transduction in schizophrenia: migration to the membrane when activated by a variety of signals such as changes in intracellular calcium concentration; specificity as to the fatty acid at the second carbon of the phospholipid moiety that initiates production of prostaglandins and other lipid-based messengers; regulation by dopamine and glutamate (neurotransmitters implicated in schizophrenia).

Our original genetic study into cytosolic phospholipase $A_{2}$ in schizophrenia was in fact two separate analyses (Hudson et al, 1996). Initially, an association-type study compared 65 patients with schizophrenia with matched healthy controls and found an association between a marker near the cytosolic phospholipase $\mathrm{A}_{2}$ gene and schizophrenia. Spurious results may arise with association-type studies and, therefore, we undertook a haplotype relative risk study of 44 families including a proband with schizophrenia, which resulted in the same positive association. A more recent study employing a second marker actually within the intron of the cytosolic phospholipase $A_{2}$ gene also found an association between cytosolic phospholipase $\mathrm{A}_{2}$ and schizophrenia (Peet et al, 1998). Again, a haplotype relative risk study of $\mathbf{5 0}$ families replicated this finding (Wei et al, 1998). Other studies (Price et al, 1997) employing association strategies on smaller sample sizes have not replicated our findings.

The majority of genetic data and biochemical data to date suggest the cytosolic phospholipase $\mathrm{A}_{2}$ gene on chromosome 1 plays a role in increased vulnerability to schizophrenia. The precise determination of the specific phospholipase $A_{2}$ enzyme(s) involved in schizophrenia may well prove critical in the development of lipid-based strategies for improved treatment of schizophrenia.

Hudeon, C. J., Kennedy, J. L., Gotowilec, A., et al (1996) Genetic variant near cytosolic phospholipase $A_{2}$ associated with schizophrenia. Schizophrenia Research. 21, III-116.
Peet, M., Ramchand, C. N. \& Lee, J. (1Ss) Association of the Ban I dimorphic site at the human cytosolic phospholipase A2 gene with schizophrenia. Psychiatric Genetics, 191-192.

Price, S., Fox, H., St Clair, et al (1997) Lack of association between schizophrenia and a polymorphism close to cytosolic phospholipase A2 gene. Psychiatric Genetics, 7, III-140.

Walloer, N. P., Fox, H. C. \& Whallex L J (19se) Lipids and schizophrenia. British journal of Psychiotry 174. $101-104$

Wed, J., Lee, K. H. \& Hummings, G. P. (1998) is the CPLA2 gene associated with schizophrenia? Moleculor Psychiatry 3, 480-48I.

C. Hudson Department of Psychiatry, Stratford General Hospital, 90 John Street South, Stratford. Ontario, Canada N5A 2 Y8

\section{Hallucinatory assumptions}

Sir: Feinberg \& Guazelli (1999) constructed an elaborate theory of subcortical motor system dysfunction to explain schizophrenia. Whether or not it explains some symptoms, it certainly cannot explain schizophrenic auditory hallucinations for two fundamental reasons: non-verbal auditory hallucinations occur in many disparate non-psychotic states, and complex verbal auditory hallucinations occur in all psychoses.

Feinberg \& Guazelli divided auditory hallucinations into four broad classes, despite conceding that there can be phenomenological overlap, and that such a classification was oversimplified. If Occam is right, as he usually is, then this scheme is overcomplicated. The literature on musical auditory hallucinations (Gordon, 1997) is quite clear that their basic phenomenology is similar, whether these occur in psychosis, delirium, ear disease, mysticism, intoxication, fever, etc. A simple common explanation was offered, namely inner-ear hyperirritability. However, one does not have to accept this explanation to realise that there must be some unitary mechanism for the production of auditory hallucinations, although of course their interpretation will vary enormously depending on psychiatric, religious or medical context. Anyone arguing that voices have nothing to do with music needs to show that these auditory hallucinations have different causes. If anyone knows of any diseases, risk makers or risk markers associated with verbal but not non-verbal auditory hallucinations (music, noises, tinnitus), please could they let me know, as I cannot find any. Feinberg \& Guazelli cite Kraepelin's 1919 book which has detailed descriptions of all sorts of simple and complex auditory hallucinations in schizophrenia.

Verbal auditory hallucinations can become particularly complex in schizophrenia when associated with loss of insight or incorporated in delusional systems. Peralta \& Cuesta (1999) convincingly showed that first-rank symptoms, particularly voices, are just as common in six other psychoses as in schizophrenia. Hence, Feinberg \& Guazelli's theory, however plausible for schizophrenia, is a non-starter for explaining auditory hallucinations, since it cannot explain first-rank symptoms in non-schizophrenic psychoses. All other psychological theories specific to schizophrenia are equally suspect, especially linguistic ones which, in addition, make no attempt to explain non-verbal auditory hallucinations.

Felnberz, L \& Guarelly, M. (1999) Schizoprehnia - a disorder of the corollary discharge systems that integrate the motor systems of thought with the sensory systems of consciousness. British journal of Psychiotry. 174. 196-204.

Gordon, A. G. (1917) Do musical hallucinations always arise from the inner ear? Medical Hypotheses, 49, III-122.

Poralta, V. \& Cuesta, M. J. (1999) Diagnostic significance of Schneider's first-rank symptoms in schizophrenia. Comparative study between schizophrenic and non-schizophrenic psychotic disorders. British journal of Psychiotry 174, 243-248.

A. G. Gordon 32 Love Walk, London SE5 8AD

\section{Amiodarone and psychiatric symptoms}

Sir: The pharmacokinetics of the class III antiarrhythmic amiodarone make it unlikely that its withdrawal was the reason for the dramatic clinical improvement observed within one week in the patient described by Ambrose \& Salib (1999).

Amiodarone, a highly lipophilic drug, is extensively distributed into tissues, with a half-life as long as $\mathbf{1 0 0}$ days. Its therapeutic effect can last in excess of one month after withdrawal of long-term oral therapy (Latini et al, 1984).

If amiodarone is implicated in triggering psychiatric symptoms, then I would propose that the benefits of stopping this agent might not be observed until many weeks or even months after withdrawal of therapy.

Ambrose, A. \& Saltb, E. (INe) Amiodarone-induced depression. British journal of Psychiotry 174, 366-367. 
Letind, R., Tognond, G. A Ketes, R. E. (19e4) Clinical pharmacokinetics of amiodarone. Clinicol Pharmocokinetics, 9, 136-156.

J. Nicholson Royal Edinburgh Hospital, Morningside Terrace, Edinburgh EHIO SHF

\section{Regarding the 'difficult patient'}

Sir: I read Hinshelwood's (1999) editorial soon after assessing a 16-year-old patient with severe but by no means unusual problems. The patient had been referred by a social worker and not by a psychiatrist, and came from a background characterised by severely disrupted parenting, neglect and multiple forms of abuse. There was a twoyear history of repeated self-cutting and drug misuse. In the previous six months the patient had undergone three brief psychiatric admissions to two adolescent units following repeated suicidal overdoses and escalating risk-taking behaviour. The referring social worker told me that the patient had been described to her as "untreatable". I found the last discharge summary thought-provoking. The multi-axial diagnosis read as follows:

\section{I nil \\ II nil \\ III nil \\ IV nil}

V Anomalous parenting with repeated loss of love relationships, emotional abuse, neglect

\section{Moderate social disability}

I was astonished that the attending psychiatrists failed to come up with any Axis I or Axis II diagnoses. It is possible that this reflects a failure of current diagnostic systems to describe severely disturbed adolescents. Such adolescents are often (but inaccurately) diagnosed as conduct disordered (Lewis et al, 1984). It is generally held that their age excludes a diagnosis of personality disorder, but there is evidence for the validity of borderline personality disorder in children (Greenman et al, 1986). An alternative term, complex post-traumatic stress disorder, has been proposed (Herman, 1992), and could also be considered. I was alarmed at the "untreatable" label, which is at variance with empirical findings on the treatment of borderline personality disorder, for example Najavits \& Gunderson (1995) describing adults, and Meijer et al (1998) describing adolescents.
In any event, I suspect that the above multi-axial formulation reflected an emotional failure rather than an intellectual failure on the part of the professionals concerned. I would agree with Hinshelwood that we often distance ourselves from such patients because of the intensity of their emotional contact with us, their refusal to conform to our ideas of sick-role behaviour and, I would add, the horror of their life histories. I believe that this reaction is stronger with adolescent patients because of the parental feelings that they evoke in professionals. Also, the history of maltreatment is sometimes ongoing as the patient is often still residing with or is in contact with the perpetrators of the abuse. These challenging patients are both treatable and in need of treatment, and we should not evade our responsibilities towards them.

Greenman, D. A., Gunderson, J. G., Cane, M., of a (1986) An examination of the borderline diagnosis in children. Americon foumol of Psychiotry, 143, 998-1003.

Herman, J. L. (1992) Trouma and Recovery, From Domestic Abuse to Political Terror. New York: Basic Books.

Hinshehwood, R. D. (199) The difficult patient. The role of 'scientific psychiatry' in understanding patients with chronic schizophrenia or severe personality disorder. British journal of Psychiatry, 174, 187-190.

Lowis, D. O., Lewhs, M., Unger, L., ef of (1984) Conduct disorder and its synomyms: diagnoses of dubious validity and usefulness. American journal of Psychiotry 141, 514-519.

Melfer, M., Goedhart, A.W. Theffers, P. D. A. (IS9) The persistence of borderline personality disorder in adolescence. Journal of Personality Disorders, 12, 13-22.

Najevits, L. M. \& Gunderson, J.G. (Ises) Better than expected: improvements in borderline personality disorder in a 3-year prospective outcome study. Comprehensive Psychiotry, 36, 296-302.

D. Hartman Huntercombe Manor Hospital, Huntercombe Lane South, Taplow, Berkshire SL.6 OPQ

\section{'Scientific' psychiatry}

Sir: It was a pleasure to read Hinshelwood's (1999) editorial. It was a thoughtful and sensitive discussion of the role of what he termed 'scientific psychiatry' within the diagnosis and treatment of paranoid schizophrenia and severe personality disorder. He skilfully highlighted what seems to be a clear dichotomy in the profession between evidence-based and more interpersonal approaches to knowledge within psychiatry (Hunter, 1996). It did seem, however, that the editorial fuelled this divide by restricting itself to only the potential faults of the former. Hinshelwood seemed to claim that the 'scientific' approach compromised patients' management by dehumanising both them and their psychiatrists. Patients would become illnesses to be treated and psychiatrists would avoid personal involvement.

This approach raises two issues. First, the scientific approach to these illnesses is not all negative. The understanding of schizophrenia, for example, over the course of this century, using a scientific approach, has resulted in treatment which has transformed, markedly 'humanised', and partially destigmatised many sufferers' lives.

Second, the nature of knowledge has been debated for centuries (Ayer, 1956). However, some literature makes it seem as if we had just discovered the problem. As psychiatrists, we deal with the full breadth of humanity and it thus seems naïve to approach epistemology by simplistic polarising of the issues. Surely the solutions are more likely to be found using models incorporating multiple forms of knowledge acquisition, and a more mature approach to a very complex and longstanding philosophical issue.

Ayer, A. J. (1956) The Problem of Knowledge. Harmondsworth: Penguin.

Hinahehwood, R. D. (1999) The difficult patient. The role of 'scientific psychiatry' in understanding patients with chronic schizophrenia or severe personality disorder. British journal of Psychiatry, 174, 187-190.

Hunter, K. (1996) "Don't think zebras": uncertainty. interpretation and the place of paradox in clinical education. Theoretical Medicine, 17. 225-241.

P. Webster c/o Department of Eating Disorders, Institute of Psychiatry, De Crespigny Park, Denmark Hill, London SE5 8AF

\section{HoNOS 65+ glossary}

Sir: The HoNOS 65+ glossary submitted in December 1998 (Burns et al, 1999) has been superseded. The current glossary is available via www.umds.ac.uk/psychiatry/soap/ and from the office of the College Research Unit HoNOS 65+ Implementation Group (tel. 0181690 5647). Details of a HoNOS 65+ training service for England and $W$ ales from 1 September 1999 are now also available.

Burns, A., Beevor, A., Lellilot, P., ef of (1999) Health of the Nation Outcome Scales for Elderly People (HoNOS 65+). Glossary for HoNOS 65+ score sheet. British journol of Psychiotry. 174, 435-438.

A. J. D. Macdonald College Research Unit, HoNOS 65+ Implementation Group, 4th Floor. Ladywell Unit, Lewisham Hospital, London SEI3 6LH 